\title{
Reverse Osmosis Treatment of Wastewater for Reuse as Process Water-A Case Study
}

\author{
Marjana Simonič
}

check for updates

Citation: Simonič, M. Reverse Osmosis Treatment of Wastewater for Reuse as Process Water-A Case Study. Membranes 2021, 11, 976. https://doi.org/10.3390/ membranes11120976

Academic Editor: Asuncion Maria Hidalgo

Received: 18 November 2021 Accepted: 9 December 2021 Published: 10 December 2021

Publisher's Note: MDPI stays neutral with regard to jurisdictional claims in published maps and institutional affiliations.

Copyright: (C) 2021 by the author. Licensee MDPI, Basel, Switzerland. This article is an open access article distributed under the terms and conditions of the Creative Commons Attribution (CC BY) license (https:/ / creativecommons.org/licenses/by/ $4.0 /)$.
Faculty of Chemistry and Chemical Engineering, University of Maribor, 2000 Maribor, Slovenia; marjana.simonic@um.si

\begin{abstract}
The aim of this work was to purify mixed wastewater from three different production processes in such a manner that they could be reused as process water. The maximum allowed concentrations (MAC) from the Environmental Standards for emissions of substances released into surface water were set as target concentrations. Wastewaters contained solid particles, sodium, aluminium, chloride, and nitrogen in high amounts. Quantitatively, most wastewaters were generated in the production line of alumina washing. The second type of wastewater was generated from the production line of boehmite. The third type of wastewater was from regeneration of ion exchangers, which are applied for feed boiler water treatment. The initial treatment step of wastewater mixture was neutralisation, using $35 \% \mathrm{HCl}$. The precoat filtration followed, and the level of suspended solids was reduced from $320 \mathrm{mg} / \mathrm{L}$ to only $9 \mathrm{mg} / \mathrm{L}$. The concentrations of ions, such as aluminium, sodium and chlorides remained above the MAC. Therefore, laboratory reverse osmosis was applied to remove the listed pollutants from the water. We succeeded in removal of all the pollutants. The concentration of aluminium decreased below $3 \mathrm{mg} / \mathrm{L}$, the sodium to $145 \mathrm{mg} / \mathrm{L}$ and chlorides to $193 \mathrm{mg} / \mathrm{L}$. The concentration of nitrate nitrogen decreased below $20 \mathrm{mg} / \mathrm{L}$.
\end{abstract}

Keywords: alumina production; reverse osmosis; fouling; wastewater reuse

\section{Introduction}

Alumina $\left(\mathrm{Al}_{2} \mathrm{O}_{3}\right)$ is considered a basic catalytic material support due to its good mechanical properties, such as high strength, chemical and physical stability, additionally, its high thermal resistance, and thermal conductivity [1]. Boehmite (AlOOH) is used as the raw material for the preparation of alpha and gamma-alumina phases whose properties such as morphology, specific surface area, and porosity, depend strongly on the boehmite structure [2].

The disposal of washing water into the environment is not allowed without treatment, because some parameters, such as $\mathrm{Al}, \mathrm{Na}$ and $\mathrm{Cl}$, exceed the maximum allowed values [1]. Water impurities concentrate during boiler operation. Boiler water must be softened properly before use. However, without periodic water removal (blowdown), problems such as scale deposits, corrosion and embrittlement may occur [3]. A study was reported, conducted on the utilisation of a simulated boiler blowdown for incorporation into cement-based materials. The results indicate that the use of waste brine in cemented backfill applications is feasible. The phosphate addition could result in the formation of deposits such as iron phosphate. Phosphate corrosion is assumed as a significant concern in phosphate treated steam boilers [4]. Basic feedwater treatment involves ion exchange. For existing industries operating at a low scale, resin-assisted separation continues to offer an attractive option [5]. After regeneration of an ion exchanger, acidic and alkaline effluents are generated, containing chlorides, sulphates, nitrates, silicates, etc.

Reuse of wastewater is recognised in most water-scarce countries [6]. Instead of discharging industrial effluents into rivers and streams, reverse osmosis (RO) membranes can be used to treat the wastewater and reuse it as process water in companies. Spiral wound modules (SWMs) are most widely adopted among the commercially available RO 
membrane modules [7]. The analysis of the design of spiral wound modules and correlation of experimental and model values can help to identify the module geometry and spacer design for specific applications [8]. The permeability coefficients with the feed spacer design have a relevant impact on the performance of $\mathrm{RO}$ membranes in terms of production, permeate quality and specific energy consumption [9]. This is due to the relationship between the feed spacer geometry and pressure drop and concentration polarisation phenomena. The operation of an $\mathrm{RO}$ system deals with the impact of fouling, [10] which is the main concern of this technology and along with optimal operational conditions the main thing responsible for losing performance and efficiency in a long term-operation [11]. Spiral wound modules offer ease of operation, fouling control, and a high permeation rate and packing density. Applications of spiral wound modules include desalination, water treatment, water reclamation and treatment of industrial wastewater. A water recycling system has been documented using RO technology for the treatment of oleochemical wastewater [12]. The fouled RO membrane required a high operating pressure in order to obtain a consistent permeate flow. In general, $\mathrm{RO}$ membranes are subjected to surface fouling and scaling, which can pose a significant problem when reverse osmosis is used [13]. Scaling is one of the limiting factors for increasing the flux recovery rate and improving the efficiency of the process [14]. It is well known that filtration prior to RO is essential for maintaining efficiency and protecting the membranes' functions. The use of RO membranes largely reduces the chemical consumption when membrane separation is coupled with chemical treatment, due to the capability of the RO membranes of removing dissolved solids [12]. The application of the RO process compared to other conventional thermal technologies for desalination of brackish water has increased remarkably, due to its high purification efficiency at low cost, and low energy consumption [15].

The main objective of the present study was to investigate the possibilities of recycling mixed wastewater from three different processes: The first after alumina washing, the second after boehmite production and a third from the regeneration of ion-exchangers for feed boiler water treatment. The chemical analyses of individual wastewaters did not differ much, therefore, wastewater from all three lines was collected in a feed tank, neutralised, and filtered using precoat filters. This was followed by RO treatment using two selected membranes, FILMEC XLE (Dow) and ESPA (Nitto), chosen from among the major membrane manufacturers. Treatment was tested in two membrane modes: With and without concentrate recycling. The quality of the RO permeate after both modes was compared with the Slovenian Regulations for water discharge into the environment. The organic content was determined, expressed as chemical oxygen demand (COD).

\section{Materials and Methods}

Alumina washing waters are collected in a feed reservoir. The alumina is firstly washed in an $\mathrm{HCl}$ acid solution and then filtered. The solid particles and the solution are separated. The solution contains large amounts of inorganic compounds, and must be treated before it is released into the environment. The second wastewater is generated after boehmite washing. Boehmite is aluminium oxide hydroxide that forms from $\mathrm{Al}(\mathrm{OH})_{3}$. The lattice spacing in the material is $0.117 \mathrm{~nm}$. The structure [2,16] as well as hydrophobicity, light transmittance, thermal stability, and mechanical durability [17] has been characterised extensively in the literature. Wastewater flows into the decanter, and it is then mixed with the washing water from the alumina. The third type of wastewater is generated after regeneration of an ion exchanger for boiler water treatment.

The amount of water from alumina washing is $72,000 \mathrm{~m}^{3} / \mathrm{y}$, from boehmite $14,500 \mathrm{~m}^{3} / \mathrm{y}$ and from boiler water 14,400 $\mathrm{m}^{3} / \mathrm{y}$. In such ratios (5:1:1) wastewater was mixed in the $100 \mathrm{~m}^{3}$ feed tank in the laboratory.

The feed solution after precoat perlite filtration flowed from the tank through the valve and pump to a Culligan Aqua-Cleer RO system. The system was equipped with volume counters (2) and pressure gauges (3), as seen from Figure 1. The system allows transmembrane pressure (TMP) up to 15 bar. The sample flows through the $80 \mu \mathrm{m}$ filter 
and $5 \mu \mathrm{m}$ filter for removal of the bigger particles. Such pre-treated solution is gathered in a feed tank (4). The permeate and retentate were withdrawn continuously from the system in the initial four experiments. In the final experiment the permeate and concentrate were recycled into the feed tank. The capacity was $1.5 \mathrm{~L} / \mathrm{h}$ for the permeate and $1.9 \mathrm{~L} / \mathrm{h}$ for the retentate at room temperature.

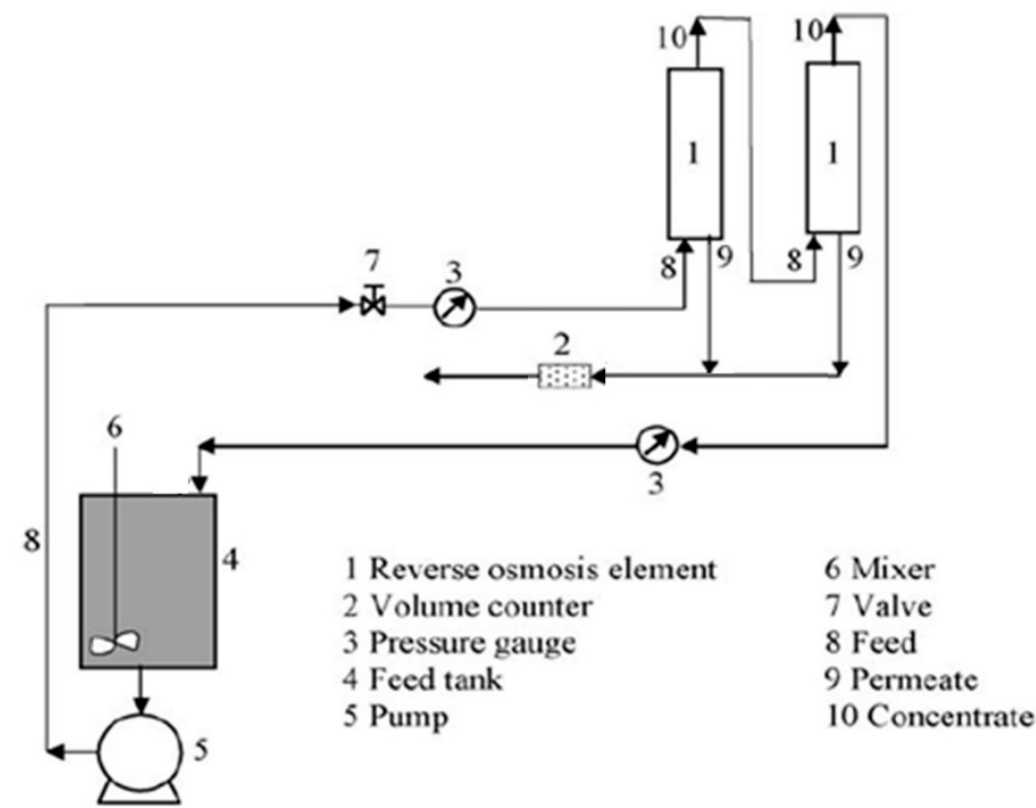

Figure 1. Schematic RO process.

The feed samples and permeate were taken at the end of the trial and subsequently analysed. The wastewater flux was measured after every repeated trial with mixed wastewater.

Dow-FILMTEC XLE (DuPont-Filmtec, Wiesbaden, Germany) and ESPA-2521 (Nitto, Nottinghamshire, UK) RO membranes were used with the properties listed in Table 1 . The membrane module dimensions were $0.287 \mathrm{~m}$ in length and $0.117 \mathrm{~m}$ in diameter.

Table 1. The RO membranes' characteristics.

\begin{tabular}{ccc}
\hline Parameter & FILMTEC XLE-2521 & ESPA-2521 \\
\hline Producer & DuPont-Filmtec (Germany) & Hydranautics, Nitto (UK) \\
$P_{\max }$ & $41 \mathrm{bar}$ & $22 \mathrm{bar}$ \\
$T_{\max }$ & $45^{\circ} \mathrm{C}$ & $45^{\circ} \mathrm{C}$ \\
$p H$ & $2-11$ & $2-10$ \\
Material/Type & Spiral wound composite polyamide & Spiral wound composite polyamide \\
\hline
\end{tabular}

The analyses of the feed wastewater and permeate were performed according to ISO Standards in three replicates. The Standard methods are summarised in Table 2. The analyses were chosen in accordance with the Slovene legislation for wastewater emission into the environment [18]. Important parameters among the general parameters are suspended solids mass concentration and $\mathrm{pH}$. Absorbance at $436 \mathrm{~nm}$ was measured as an indication of inorganic contamination. The sum of all organic compounds in the water samples was determined as COD. Inorganic species are measured as chloride, sulphate and nitrate ions using Ion chromatography (IC). Metals ( $\mathrm{Na}, \mathrm{Cu}, \mathrm{Cr}, \mathrm{Ti}, \mathrm{Zn}, \mathrm{Ni}, \mathrm{Mg}$ ), including $\mathrm{Al}$, were determined by inductively coupled plasma and mass detector (ICP-MS). $\mathrm{SiO}_{2}$ was determined spectrophotometrically. Suspended solids (SS) were analysed with an Imhoff funnel. 
Table 2. The methods used for wastewater chemical analyses.

\begin{tabular}{ccc}
\hline Parameter & Standard Method & Apparatus \\
\hline$T\left({ }^{\circ} \mathrm{C}\right)$ & ISO 10523 & Thermometer \\
$p H$ & ISO 10523 & pH-meter, MA 5740 \\
$A(436 \mathrm{~nm})$ & SIST EN ISO 7887 & Spectrophotometer Carry 100 \\
$\mathrm{K}(\mathrm{mS} / \mathrm{cm})$ & EN 27888 & Conductivity-meter \\
$\mathrm{COD}\left(\mathrm{g} / \mathrm{L} \mathrm{O}_{2}\right)$ & ISO 6060 & Digestion, Titration \\
$\mathrm{SS}$ & ISO 38409-H9-2 & Imhoff funnel \\
$\mathrm{Metals}^{\mathrm{C}}$ & $\mathrm{ISO} \mathrm{17294-2}$ & ICP-MS Agilent 7700x \\
Ions $\left(\mathrm{Cl}, \mathrm{SO}_{4}, \mathrm{NO}_{3}\right)$ & ISO 10304-1 & IC Metrohm IC 761 \\
Phosphorus & ISO 6878 & Spectrophotometer Carry 100 \\
Silicium dioxide & SM4500-SiO2C & Spectrophotometer Carry 100 \\
\hline
\end{tabular}

\subsection{Calculations}

Rejection $R$ was determined according to Equation (1):

$$
R=\left(c_{\mathrm{f}}-c_{p}\right) / c_{\mathrm{f}}
$$

Concentration factor $f_{\mathrm{c}}$ was determined according to Equation (2):

$$
f_{\mathrm{c}}=1 /(1-q)
$$

where

$c_{\mathrm{f}}=$ concentration in the feed solution $(\mathrm{mg} / \mathrm{L} /)$

$c_{\mathrm{p}}=$ concentration in the permeate solution $(\mathrm{mg} / \mathrm{L} /)$

$q=$ water flow $(\mathrm{L} / \mathrm{h})$

One of the most common methods of determination of fouling is the membrane filtration index (MFI) [19]. Cake layer formation is proposed as the dominant mechanism. The MFI test is performed by filtration of water through a 0.45 um filter with constant pressure in dead-end mode. The MFI can be calculated as seen from Equation (3) [19]:

$$
\frac{t}{V}=\frac{\mu R_{m}}{T M P \cdot A}+\frac{\mu I}{2 T M P A^{2}} V
$$

By plotting $t / V$ versus $V$ (permeate volume) the MFI is defined as the slope of a straight line after the initial linear section. TMP represents transmembrane pressure (bar), $A$ is the membrane area $\left(\mathrm{m}^{2}\right), R_{\mathrm{m}}$ is the membrane resistance $\left(\mathrm{m}^{-1}\right), \mu$ is viscosity (Pa. $\mathrm{s}$ ) and $t$ is the filtration time (s). The higher the fouling potential for a given solution, the higher will be the MFI value.

\subsection{SEM Imaging}

The washing solutions after membrane cleaning were examined with an FEI, SIRION400 field emission scanning electron microscope (FESEM).

\section{Results and Discussion}

\subsection{Physico-Chemical Analyses}

After filtration of all samples, the parameters listed in Table 3 were measured in the wastewater samples. Wastewater was taken from the washing process line 10 times and mixed. Such average sample was analysed for all parameters according to the Slovenian Regulations. Washing water in alumina production is denoted in Table 3 as WW1, washing water in boehmite production is denoted in Table 3 as WW2, and water after regeneration during feed boiling water condition as WW3. The results are gathered in Table 3. $\mathrm{Al}$ exceeded $3 \mathrm{mg} / \mathrm{L}$ in WW1. The suspended solids' mass concentration was too high in the washing water in boehmite production (WW2), sodium was above the MAC and aluminium was very high, measured at $33 \mathrm{mg} / \mathrm{L}$. In WW3 phosphorus was just above the MAC and the $p H$ value was too alkaline. Absorbance at $436 \mathrm{~nm}$ exceeded the MAC for all 
samples. MAC represents the maximum allowed concentration according to the Slovenian Regulations [18]

Table 3. Measured chemical parameters after alumina washing.

\begin{tabular}{|c|c|c|c|c|}
\hline Parameter & $\begin{array}{c}\text { MAC } \\
(\mathrm{mg} / \mathrm{L})\end{array}$ & $\begin{array}{c}\text { c (WW1) } \\
(\mathrm{mg} / \mathrm{L})\end{array}$ & $\begin{array}{c}\text { c (WW2) } \\
(\mathrm{mg} / \mathrm{L})\end{array}$ & $\begin{array}{c}\text { c (WW3) } \\
(\mathrm{mg} / \mathrm{L})\end{array}$ \\
\hline $\mathrm{Al}$ & 3 & 8.41 & 33.03 & 1.13 \\
\hline $\mathrm{SiO}_{2}$ & 250 & 0.74 & 2.86 & 40.1 \\
\hline $\mathrm{Na}$ & 200 & 152 & 245 & 166 \\
\hline $\mathrm{Cu}$ & 0.5 & 0.01 & 0.01 & 0.01 \\
\hline $\mathrm{Cr}$ & 0.5 & 0.08 & 0.006 & 0.003 \\
\hline $\mathrm{Ti}$ & 1 & 0.001 & 0.001 & 0.001 \\
\hline $\mathrm{Fe}$ & 2 & $<0.1$ & $<0.1$ & 0.17 \\
\hline $\mathrm{Zn}$ & 2 & $<0.01$ & 0.02 & 0.14 \\
\hline $\mathrm{Ni}$ & 0.5 & $<0.001$ & $<0.001$ & 0.003 \\
\hline $\mathrm{Mg}$ & 10 & 1.7 & 0.1 & 0.3 \\
\hline $\mathrm{N}-\mathrm{NH}_{3}$ & 10 & 21.1 & 0.06 & 0.2 \\
\hline $\mathrm{N}-\mathrm{NO}_{3}$ & 20 & 11 & 9.2 & 9.3 \\
\hline $\mathrm{SO}_{4}$ & 2000 & 22.7 & 15.6 & 15.7 \\
\hline $\mathrm{PO}_{4}$ & 1 & $<0.05$ & 0.08 & 1.03 \\
\hline $\mathrm{Cl}$ & 250 & 21 & 16 & 203 \\
\hline TOC & 30 & 8 & 9 & 7 \\
\hline$S S$ & 3 & 9 & 11 & 0.1 \\
\hline
\end{tabular}

\subsection{Pretreatment with Precoat Filtration}

The mixture of wastewater streams was neutralised to $\mathrm{pH}=7$ using $\mathrm{HCl} 35 \%$ (weight percents). An aliquot of $45 \mathrm{~L}$ of the mixture was vacuum filtered through $2 \mathrm{~cm}$ of perlite layer (200 g). The emphasis was on suspended solids‘ removal. The removal was $96 \%$, which means that the measured concentration decreased down to $11 \mathrm{mg} / \mathrm{L}$. The results are in good agreement with the reported study showing a 95\% reduction in turbidity [20]. The concentration was acceptable for further treatment. Settleable solids decreased below $0.1 \mathrm{mg} / \mathrm{L}$ and were not problematic. Among metals Al was measured, and the removal was $64 \%$, which was still above $3 \mathrm{mg} / \mathrm{L}$. Other parameters from Table 3 were below the MAC.

During the second trial the same aliquot of mixture was filtered through $350 \mathrm{~g}$ of a $2.8 \mathrm{~cm}$ perlite layer. The results were similar compared with the first trial, but the filtration time was prolonged by some $15 \mathrm{~min}$. The suspended solids' removal was 97\%, which means that the measured concentration decreased down to $9 \mathrm{mg} / \mathrm{L}$. It was acceptable for further treatment. Settleable solids decreased below $0.1 \mathrm{mg} / \mathrm{L}$, and were not problematic. Among metals $\mathrm{Al}$ was measured, and the removal was $66 \%$, which was still above $3 \mathrm{mg} / \mathrm{L}$. Other parameters were below the MAC.

According to the results and the literature [21] it could be concluded that increasing the amount of precoat did not improve the regeneration result.

\subsection{Filtration with a Reverse Osmosis Membrane}

The linear plot for permeability with Millipore water was determined using both RO membranes, FILMTEC XLE-2521 (XLE) and ESPA-2521 (ESPA), as shown in Figure 2. Similar values were also obtained in another study [22]. The permeability of both membranes was followed in the range from 6 bar to 10 bar. A small deviation was observed at 7 bars with both membranes, indicating that the highest flux was reached at 7 bar and 10 bar TMP. The permeate flux remained very similar to that of the trial at 10 bars with concentrate withdrawal. The wastewater fluxes were determined at $111 \mathrm{~L} /\left(\mathrm{m}^{2} . \mathrm{h}\right)$ for XLE and $112 \mathrm{~L} /\left(\mathrm{m}^{2} . \mathrm{h}\right)$ for ESPA at 10 bar. At other TMP, the flux was slightly lower compared to that at TMP $=7$ bar and TMP $=10$ bar. Therefore, 7 bar and 10 bar TMP were chosen for further trials with both membranes. The optimal TMP between 7 and 8 was reported in the literature [22,23]. 


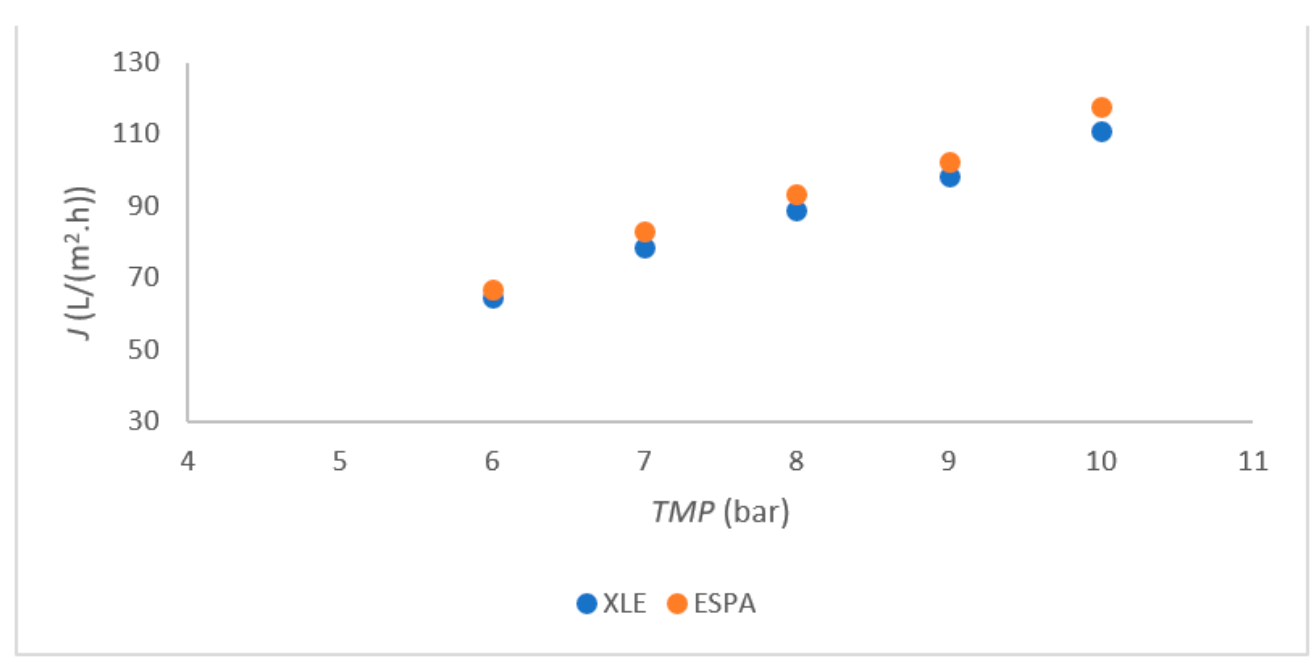

Figure 2. Flux in dependence of TMP for both membranes.

The fluxes of mixed wastewater are shown in Figure 3 for both membranes at two different TMP; 7 bar and 10 bar were chosen according to the millipore water flux and the literature [22]. The fluxes of both membranes were the same at 7 bar, and the curves overlapped each other. Slightly higher fluxes were achieved at 10 bar with ESPA compared with the XLE membrane. The same trends were observed with the time dependence: During $30 \mathrm{~min}$ the flux decreased, and then it stabilised at $25 \mathrm{~L} /\left(\mathrm{m}^{2} . \mathrm{h}\right)$ for XLE and $27 \mathrm{~L} /\left(\mathrm{m}^{2} . \mathrm{h}\right)$ for ESPA at 10 bar.

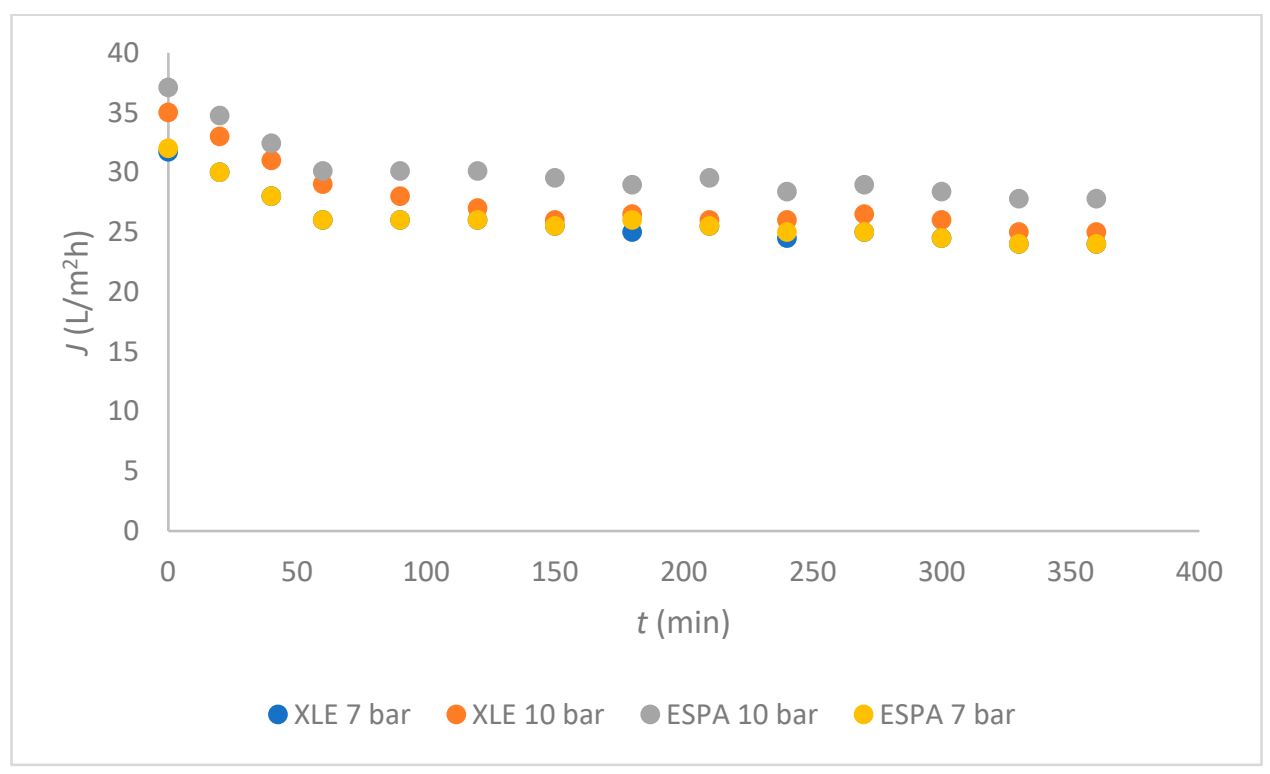

Figure 3. Flux dependent on time for both membranes.

In Figure 3, a relatively uniform flux was observed from $50 \mathrm{~min}$ to $200 \mathrm{~min}$ of $\mathrm{RO}$ operation. Also, it was very important that, after $200 \mathrm{~min}$, there was no need for cleaning for both membranes. The membranes with a higher negative surface charge and greater hydrophilicity are less prone to fouling [12]. The ESPA membrane is more hydrophilic, as seen from Figure 2, and it can be expected that fouling mechanisms would affect the ESPA membrane to a lesser extent than the XLE. This claim was confirmed, as the flux of mixed process water was higher when using ESPA compared with XLE at 10 bars (Figure 3). The results are in agreement with Koo [12]. 


\subsubsection{Chemical Analyses after RO}

After perlite filtration, wastewater from three streams was mixed in the volume ratio 5:1:1 from alumina washing, boehmite washing and wastewater after regeneration of boiler feed water, respectively. The ratio is based on actual wastewater generation in the company. Such a mixture represented the feed for an RO. The chemical analysis is shown in Table 4.

Table 4. Measured chemical parameters in the wastewater mixture (mixWW).

\begin{tabular}{ccc}
\hline Parameter & $\begin{array}{c}\text { MAC } \\
(\mathbf{m g} / \mathbf{L})\end{array}$ & $\begin{array}{c}\text { c (mixWW) } \\
(\mathbf{m g} / \mathbf{L})\end{array}$ \\
$\mathrm{Al}$ & 3 & 9.02 \\
$\mathrm{SiO}_{2}$ & 250 & 15 \\
$\mathrm{Na}$ & 200 & 229 \\
$\mathrm{Cu}$ & 0.5 & 0.01 \\
$\mathrm{Cr}$ & 0.5 & 0.08 \\
$\mathrm{Ti}$ & 1 & 0.001 \\
$\mathrm{Fe}$ & 2 & $<0.1$ \\
$\mathrm{Zn}$ & 2 & $<0.01$ \\
$\mathrm{Ni}$ & 0.5 & $<0.001$ \\
$\mathrm{Mg}$ & 10 & 1.6 \\
$\mathrm{~N}-\mathrm{NH}_{3}$ & 10 & 1.1 \\
$\mathrm{~N}^{-N O}$ & 20 & 10 \\
$\mathrm{SO}_{4}$ & 2000 & 24 \\
$\mathrm{PO}_{4}$ & 1 & $<0.05$ \\
$\mathrm{Cl}$ & 250 & 255 \\
$\mathrm{TOC}_{\mathrm{SS}}$ & 30 & 8 \\
& 3 & 2 \\
\hline
\end{tabular}

The concentrations of heavy metals were not problematic, because the measured values of all heavy metals were below the MAC, as seen from Table 4. Suspended solids decreased below $3 \mathrm{mg} / \mathrm{L}$. Exceeded were concentrations of $\mathrm{Al}$, Na and $\mathrm{Cl}$. Organic compounds were below $30 \mathrm{mg} / \mathrm{L} \mathrm{C}$. Thus, in further experiments, the focus was directed towards measurement of the mentioned parameters. The XLE membrane was applied at TMP 7 bar. All metal concentrations remained below the MAC. Suspended solids decreased to $1.2 \mathrm{mg} / \mathrm{L}$. Na decreased from 245 to $11 \mathrm{mg} / \mathrm{L}$ which is above $95 \%$. In the production process $\mathrm{Al}_{2} \mathrm{O}_{3}$ decreases with the increase of alkali concentration [24], therefore, the concentration of $\mathrm{Na}$ should be low in the permeate. The measured values were acceptable. Similarly, $\mathrm{Cl}$ decreased to $13 \mathrm{mg} / \mathrm{L}$, which also means $95 \%$ removal. Al decreased below MAC ( $3 \mathrm{mg} / \mathrm{L})$ to $1 \mathrm{mg} / \mathrm{L}$, which means $88 \%$ efficiency. Although the ammonia concentration was not problematic, it could be further reduced by lowering $\mathrm{pH}$ value below 6 [25]. The study shows ammonnia removal at $99.8 \%$.

In the next experiment ESPA was applied at $T M P=7$. The results were very similar to those of the XLE membrane: $\mathrm{Na}$ and $\mathrm{Cl}$ decreased by $96 \%$ and $\mathrm{Al}$ by $91 \%$. Suspended solids decreased to the same value of $1.2 \mathrm{mg} / \mathrm{L}$. The results of $\mathrm{NaCl}$ rejection correlated well with the reported values, around $98 \%$ for the XLE, and a little higher for the ESPA membrane at 8 bar [23].

In the third experiment the XLE membrane was tested at TMP 10 bar. Very similar results were obtained as at 7 bar. Only the efficiencies were a little lower compared with 7 bar for $\mathrm{Al}, \mathrm{Na}$ and $\mathrm{Cl}$, up to $90 \%$.

In the fourth experiment the ESPA membrane was tested at TMP 10 bar. Very similar results were obtained as at 7 bar. Only the efficiencies were a little lower compared with 7 bar, for $\mathrm{Al}, \mathrm{Na}$ and $\mathrm{Cl}$, up to $91 \%$.

The next experiments were performed with reverse osmosis in concentration mode with both membranes. The concentrate from the Aqua Cleer system was returned to the feed solution. The concentration factor was calculated at 5 . The main advantage of such treatment is decreasing of retentate quantity production and waste streams' minimisation. 
The results using ESPA are presented in Figure 4. The mass concentration of $\mathrm{Na}$ and $\mathrm{Cl}$ ions increased due to the concentration of the feed. After the treatment, the concentrations of both ions decreased below the MAC. The concentration of Na was decreased from $1678 \mathrm{mg} / 1 \mathrm{in}$ the feed to $145 \mathrm{mg} / 1$ below the MAC of $200 \mathrm{mg} / \mathrm{l}$. Due to neutralisation using $\mathrm{HCl}$ prior to precoat filtration and concentration of the $\mathrm{RO}$ feed, the concentration of chlorides in the RO feed tank was measured at $2376 \mathrm{mg} / \mathrm{l}$. The concentration of $\mathrm{Cl}$ decreased to $193 \mathrm{mg} / \mathrm{l}$, well below the MAC.

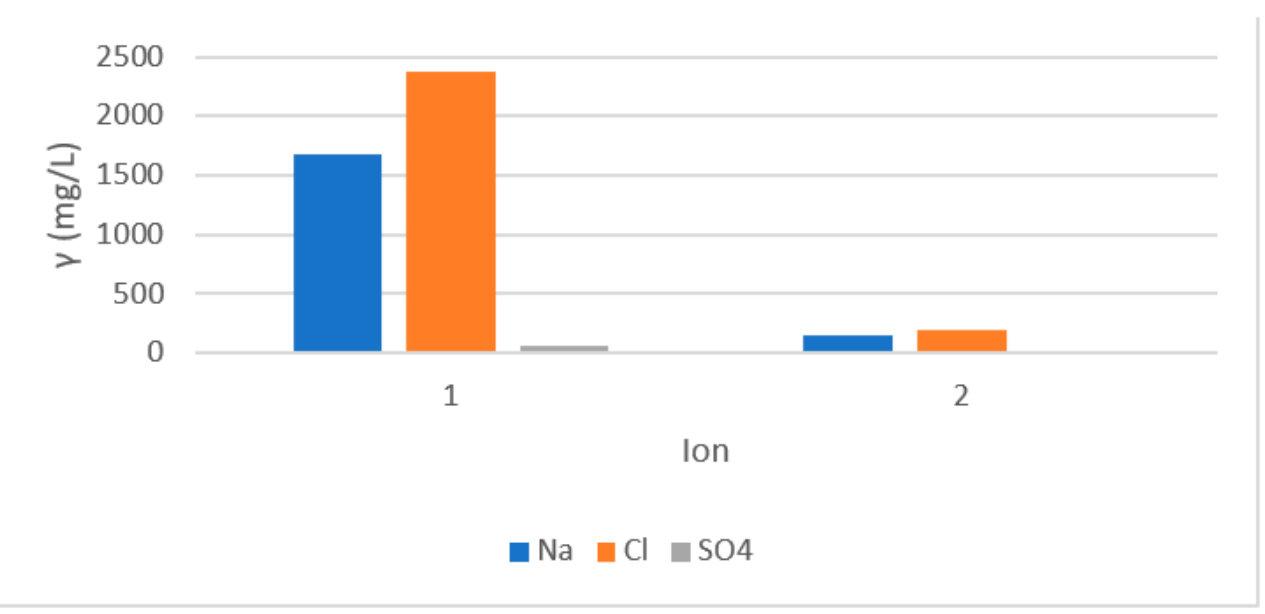

Figure 4. Mass concentration in feed (denoted 1) and permeate (denoted2).

Suspended solids were removed below $2 \mathrm{mg} / \mathrm{L}$. Al also remained below $3 \mathrm{mg} / \mathrm{L}$.

The chemical analysis of water treated with the XLE membrane was a little worse. The membrane started to foul after concentration factor 3 , therefore, the initial concentrations were lower compared with the experiment using the ESPA membrane. The concentrations of $\mathrm{Na}$, and $\mathrm{Cl}$ decreased below the MAC, but $\mathrm{Al}$ remained above $3 \mathrm{mg} / \mathrm{L}$. From the experiments we can conclude that the ESPA membrane is more appropriate for wastewater treatment and water reuse.

\subsubsection{Membrane Fouling Studies}

The MFI was determined according to the results of Equation (3). The MFI was determined for untreated wastewater and pre-treated wastewater. The formation of a cake layer was confirmed, due to the much lower fouling index after the pre-coat filtration prior to RO treatment. The MFI of untreated water was determined at $5.7 \mathrm{~s} / \mathrm{L}^{2}$, and that of pre-treated water with a precoat filter decreased to $1.9 \mathrm{~s} / \mathrm{L}^{2}$, as seen from Figure 5 . The results are in agreement with suspended solids' removal as discussed in Section 3.2.

\subsubsection{Membrane Cleaning}

In wastewater after alumina washing, different concentrations of $\mathrm{Al}, \mathrm{SIO}_{2}, \mathrm{Cl}$, and $\mathrm{Na}$ ions are still present, which contribute to the inorganic fouling on the membrane's surface. Sodium phosphate species react with the deposited scales [4]. Fouling was more alleviated using the ESPA membrane, due to intensification of the inorganic fouling. The results of flux in Figure 4 show that the flux of XLE was lower than the ESPA membrane, which was probably due to stronger interactions of the inorganic compounds with the membrane compared to the ESPA. 


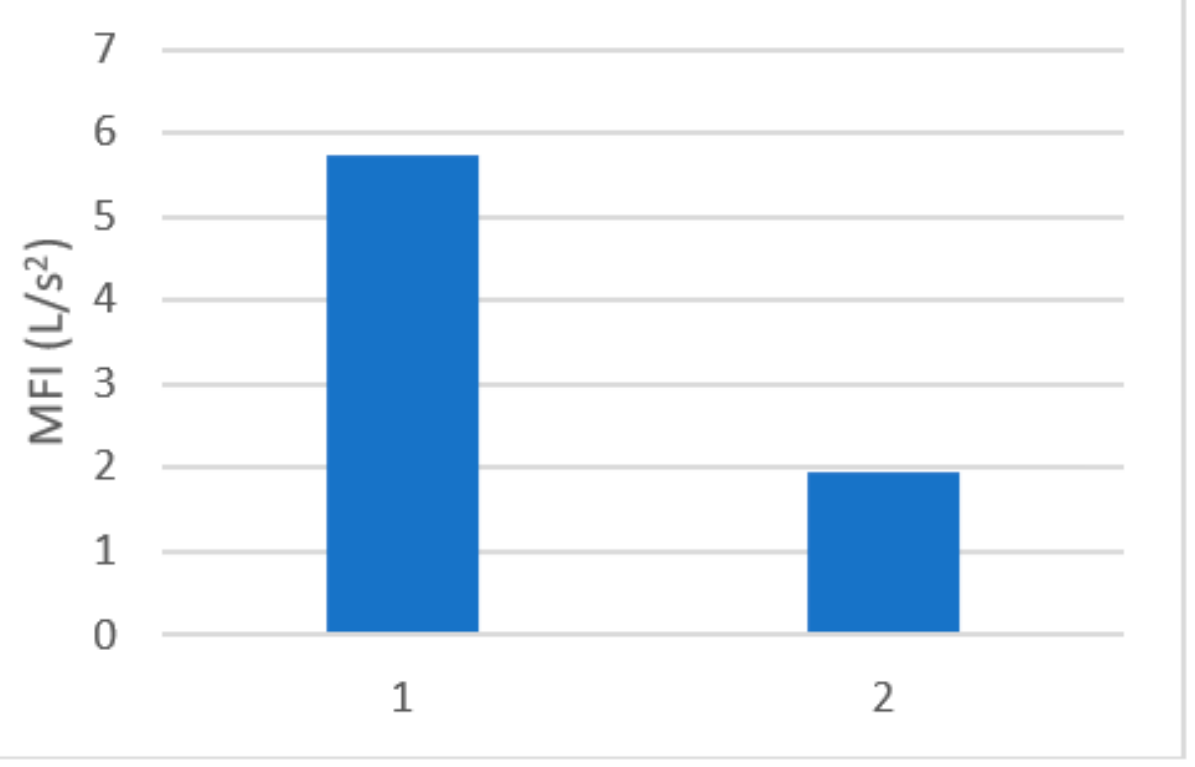

Figure 5. MFI for 1. Untreated mixed wastewater, 2. Pre-treated mixed wastewater.

After 200 min of working the membrane fouled (not shown in paper), because there was no flux and cleaning was necessary. Biofouling was controlled by UV lamp in accordance with the literature [26]. The cleaning agents were among a wide variety of chemicals, including acids $\left(\mathrm{HCl}, \mathrm{HNO}_{3}\right.$, and $\left.\mathrm{H}_{2} \mathrm{SO}_{4}\right)$, a base $(\mathrm{NaOH})$, a complexing agent (EDTA), a surfactant (SDS), and their combination. To achieve high cleaning efficiency, the effects of physical factors were studied (velocity, temperature, and time). The result showed that the two stages, caustic and detergent cleaning including NaOH-SDS followed by acid, provided an effective recovery. Since we could not disassemble the module (we had only this one), after performance of the cleaning, the effluent solution with deposits from the membrane surface was observed through SEM imaging. From Figure 6 it can be seen that small particles were washed out in a range from below $1 \mu \mathrm{m}$ up to $20 \mu \mathrm{m}$. Based on the chemical analyses it was assumed that some aggregates of $\mathrm{Al}$ and $\mathrm{SiO}_{2}$ were formed, as well as Na or Ca salts such as sulphates.

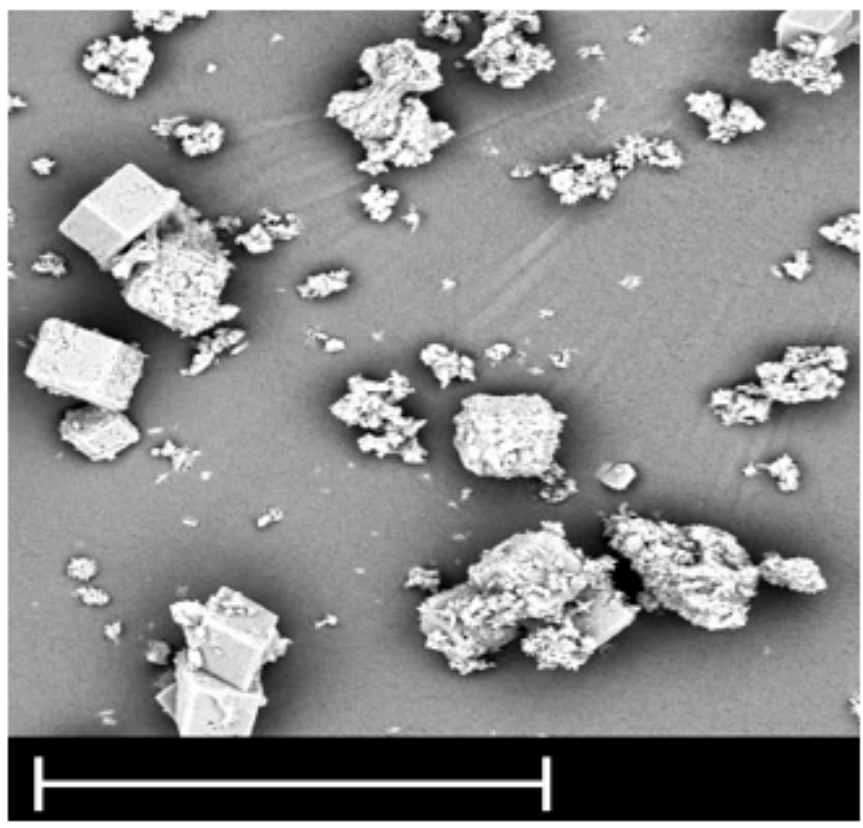

Figure 6. SEM image of deposit from the membrane after cleaning (line: $10 \mu \mathrm{m}$ ). 
Cleaning with $\mathrm{HCl}$ probably removed the $\mathrm{Ca}$ and $\mathrm{Mg}$ salts, which are soluble in acids. This finding is in good agreement with what had been observed from the water recycling plant in another study, whereby $\mathrm{NaOH}$ was found to be more effective in recovering the flux than $\mathrm{HCl}$ [12].

The cake layer forms by deposition of material on the membrane's surface rather than by penetration, in accordance with the SEM image.

\subsubsection{Process Scheme}

The process scheme was designed based on the results. Figure 7 shows the scheme of the process water treatment. The water from alumina scrubbing, wastewater generated after boehmite washing and the effluents after regeneration of an ion exchanger for boiler water treatment, were gathered in a collection tank with the volume $100 \mathrm{~m}^{3}$. After neutralisation with $35 \% \mathrm{HCl}$ the pre-coat filtration was performed using a pressure leaf (Kelly) filter. A powerful centrifugal pump is required for dosing the perlite precoat. The pre-treated water then flows on to the RO plant. The permeate is collected in a $60 \mathrm{~m}^{3}$ tank. After the treatment, the water can be reused as process water in the production process of alumina and boehmite.

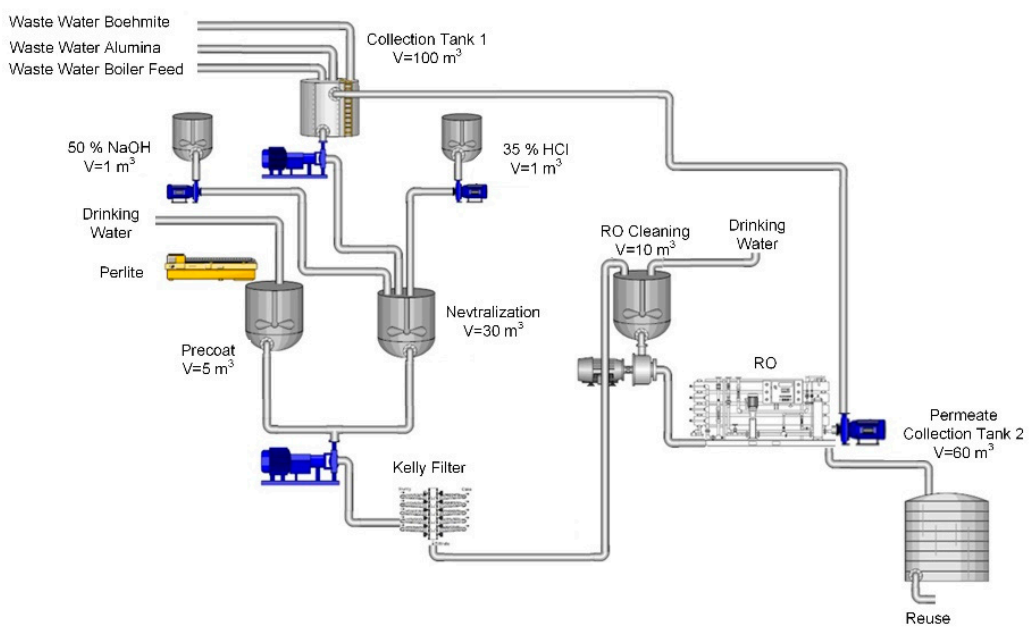

Figure 7. Schematic process scheme for wastewater treatment.

In Table 5 the costs are evaluated, based on the company's data (a) and the literature [27]. According to the results $85 \%$ of water could be reused. The cost would decrease due to water savings and reduced wastewater discharge by 82,000 Eur per year. The annual cost was calculated to be 46,630 Eur (Table 5), based on 10 years of depreciation. The payback period of less than one year indicates a high return on investment for the proposed RO wastewater treatment plant.

Table 5. Cost estimation.

\begin{tabular}{|c|c|c|}
\hline & $\begin{array}{l}\text { Total Cost } \\
\text { (Eur) }\end{array}$ & Annual Costs/10 y Depreciation (Eur) \\
\hline Cost of plant [27] & 180,000 & 18,000 \\
\hline Energy ${ }^{a}$ & 7730 & 7730 \\
\hline Chemicals [27] & 3900 & 3900 \\
\hline Labour a & 11,000 & 11,000 \\
\hline Wastewater discharge ${ }^{a}$ & 6000 & 6000 \\
\hline Total & 208,630 & 46,630 \\
\hline
\end{tabular}

a Compay's data. 


\section{Conclusions}

The study shows that the wastewaters could be treated in order to get quality for water reuse. The results confirmed that three flows could be collected, neutralised and treated further. After the mixture of differet wastewater types the water could be reused. The sodium content reduced by $95 \%$, chloride from 255 down to $193 \mathrm{mg} / \mathrm{L}$, and nitrogen below $10 \mathrm{mg} / \mathrm{L}$. Metals such as iron and aluminium decreased below detection limits. Also, the TOC was measured below $10 \mathrm{mg} / \mathrm{L}$. For RO the most suitable membrane was Hydranautics ESPA. It was calculated that 7 membrane modules with an area of $37.1 \mathrm{~m}^{2}$ each would satisfy the needs for treatment of $250 \mathrm{~m}^{3} / \mathrm{d}$. The process scheme showed that we could reduce the water consumption effectively at $85 \%$ by the proposed wastewater treatment.

Author Contributions: Conceptualization, M.S.; methodology, M.S.; investigation, M.S.; writingoriginal draft preparation, M.S.; writing — review and editing, M.S. The author has read and agreed to the published version of the manuscript.

Funding: This research was funded by the Slovenian Research Agency and Support of Research, Process Systems Engineering and Sustainable Development, Programme P2-0032.

Data Availability Statement: Data supporting the reported results can be found here: https:/ /dk. um.si/Dokument.php?id=145897 (accessed on 2 December 2021).

Acknowledgments: The author would like to thank the funders of the Slovenian Research Agency, Process Systems Engineering and Sustainable Development, Programme P2-0032.

Conflicts of Interest: The author declares no conflict of interest.

\section{References}

1. El-Shafie, M.; Kambara, S.; Hayakawa, Y. Alumina particle size effect on $\mathrm{H} 2$ production from ammonia decomposition by DBD plasma. Energy Rep. 2020, 6, 25-30. [CrossRef]

2. Mohammadi, M.; Khodamorady, M.; Tahmasbi, B.; Bahrami, K.; Ghorbani-Choghamarani, A. Boehmite nanoparticles as versatile support for organic-inorganic hybrid materials: Synthesis, functionalization, and applications in eco-friendly catalysis. J. Ind. Eng. Chem. 2021, 97, 1-78. [CrossRef]

3. Afroughsabet, V.; Zhao, P.; Peterson, K.; Shvarzman, A.; Gitarts, A. Evaluation of mortar produced with boiler blowdown brine. Constr. Build. Mater. 2021, 278, 122459. [CrossRef]

4. Pourabdollah, K. Fouling formation and under deposit corrosion of boiler firetubes. J. Environ. Chem. Eng. 2021, 9, 104552. [CrossRef]

5. Taqvi, S.A.A.; Sohail, M.; Uddin, F. Utilization of Ion-Exchange Technology for Boiler Feed Water Production-Design and Testing. Chem. Eng. 2016, 1, 26-35.

6. Manikandan, S.; Subbaiya, R.; Saravanan, M.; Ponraj, M.; Selvam, M.; Pugazhendhi, A. A critical review of advanced nanotechnology and hybrid membrane based water recycling, reuse, and wastewater treatment processes. Chemosphere 2021, 132867. [CrossRef]

7. Gu, B.; Xu, X.X.; Adjiman, C.S. A predictive model for spiral wound reverse oomosis modules: The effect of winding geometry and accurate geometric details. Comput. Chem. Eng. 2017, 96, 248-265. [CrossRef]

8. Schwinge, J.; Neal, P.R.; Wiley, D.E.; Fletcher, D.F.; Fane, A.G. Spiral wound modules and spacers: Review and analysis. J. Membr. Sci. 2004, 242, 129-153. [CrossRef]

9. Ruiz-Garcia, A.; Pestana, I.N. Feed spacer Geometries and Permeability Coefficients. Effect on the Performance in BWRO Spiral-Wound Membrane Modules. Water 2019, 11, 152. [CrossRef]

10. AlSawaftah, N.; Abuwatfa, W.; Darwish, N.; Husseini, G. A Comprehensive Review on Membrane Fouling: Mathematical Modelling, Prediction, Diagnosis, and Mitigation. Water 2021, 13, 1327. [CrossRef]

11. Cai, Y.H.; Galili, N.; Gelman, M.; Gilron, J. Evaluating the impact of pretreatment process on fouling of reverse osmosis membrane by secondary wastewater. J. Membr. Sci. 2021, 623, 119054. [CrossRef]

12. Koo, C.H.; Mohammad, A.W.; Suja, F. Recycling of oleochemical wastewater for boiler feed water using rverse osmosis membranes-A case study. Desalination 2011, 271, 178-186. [CrossRef]

13. Amma, L.V.; Ashraf, F. Brine Management in Reverse osmosis Desalination: A UAE Perspective. In Proceedings of the Advances in Science and Engineering Technology, Dubai, United Arab Emirates, 4 February-9 April 2020. [CrossRef]

14. Anis, S.F.; Hashaikeh, R.; Hilal, N. Reverse osmosis pretreatment technologies and future trends: A comprehensive review. Desalination 2019, 452, 159-195. [CrossRef]

15. Al-Karaghouli, A.; Kazmerski, L.L. Energy consumption and water production of conventional and renewable-energy-powered desalination processes. Renew. Sustain. Energy Rev. 2013, 24, 343-356. [CrossRef] 
16. Wefers, K.; Misra, C. Oxides and Hydroxides of Aluminum. V: Alcoa Technical Paper; Alcoa Laboratories: Pittsburgh, PA, USA, 1987.

17. Zhang, C.; Cheng, L.; Zhang, M.; Long, Z.; Meng, F.; Lin, H. Robust and durable transparent superhydrophobic boehmite $(\gamma-\mathrm{AlOOH})$ film by a simple hydrothermal method. Ceram. Int. 2021, 47, 11694-11701. [CrossRef]

18. Regulation, Regulation on the Emission of Substances and Heat from the Discharge of Wastewater from Municipal Watertreatment Plant, Official Gazette of Republic of Slovenia, No 45/07,63/09, 105/2010. 2007. Available online: https: / / leap.unep.org/countries/si/national-legislation/regulation-emission-substances-and-heat-discharge-waste-water (accessed on 2 December 2021).

19. Kim, D.H.; Lee, C.; Nguyen, T.T.; Adha, R.S.; Kim, C.; Ahn, S.J.; Son, H.; Kim, S. Insight into fouling potential analysis of a pilot-scale pressure-assisted forward osmosis plan for diluted seawater reverse osmosis desalination. J. Ind. Eng. Chem. 2021, 98, 237-246. [CrossRef]

20. Rani, S.R.S.; Kumar, V. Insight on appplications of low-cost ceramic membranes in wastewater treatment: A mini-review. Case Stud. Chem. Environ. Eng. 2021, 4, 100149. [CrossRef]

21. Maxim, L.D.; Niebo, R.; McConnell, E.E. Perlite toxicology and epidemiology-A review. Inhal. Toxicol. 2014, 26, 259-270. [CrossRef]

22. Madaeni, S.S.; Koocheki, S. Application of Taguchi method in the optimization of wastewater treatment using spiral-wound reverse osmosis element. Chem. Eng. J. 2006, 119, 37-44. [CrossRef]

23. Kosutic, K.; Dolar, D.; Kunst, B. On experimental parameters characterizing the reverse osmosis and nanofiltration membranes' active layer. J. Membr. Sci. 2006, 282, 109-114. [CrossRef]

24. Wang, Y.; Zhang, T.; Lyu, G.; Ma, L.; Zhang, W. Multi-material circulation optimization of the calcification-carbonation process based on material balance and phase transformation for cleaner production of alumina. J. Clean. Prod. 2021, 290, 125828. [CrossRef]

25. Shin, C.; Szcuka, A.; Jiang, R.; Mitch, W.A.; Criddle, C.S. Optimization of reverse osmosis operational conditions too maximize ammonia removal from the effluent of an anaerobic membrane bioreactor. Environ. Sci. Water Res. Technol. 2021, 7, 739-747. [CrossRef]

26. Harif, T.; Elifantz, H.; Margalit, E.; Herzberg, M.; Lichi, T.; Minz, D. The effect of pre-treatment on biofouling of BWRO membranes: A filed study. Desalination Water Treat. 2011, 31, 151-163. [CrossRef]

27. Papapetrou, M.; Cipollina, A.; La Commare, U.; Micale, G.; Zaragoza, G.; Kosmadakis, G. Assessment of methodologies and data used to calculate desalination costs. Desalination 2017, 419, 8-19. [CrossRef] 